\title{
The Management of Anaesthesia in Administration of Hyperthermic Intraperitoneal Chemotherapy Combined with Cytoreductive Surgery
}

\section{Sitoredüktif Cerrahi ile Kombine Hipertermik İntraperitoneal Kemoterapi Uygulamalarında Anestezi Yönetimi}

\author{
Betül Güven Aytaç1, İsmail Aytaç², Semih Başkan² \\ ${ }^{1}$ Ankara Etlik Zübeyde Hanım Kadın Hastalıkları Ve Doğum Eğitim Araştırma Hastanesi, Anestezi ve \\ Reanimasyon Kliniği, Ankara, Türkiye \\ ${ }^{2}$ Numune Eğitim Ve Araştırma Hastanesi, Anestezi ve Reanimasyon Kliniği, Ankara, Türkiye
}

DOI: 10.5505/aot.2012.98608

\section{ÖZET}

Peritoneal yüzey maligniteleri için sitoredüktif cerrahi ve kombine hipertermik intraperitoneal kemoterapi ile alternatif tedavi seçeneklerindeki gelişmeler anestezistler için prosedürün yeterli bilgi ile yönetimi için yeni sorumluluklar oluşturmaktadır. Bu hastaları yeterli bakımı için anestezistler hipo-hipertermi, kan kaybı, elektrolit bozuklukları, koagülopatiler, artmış kardiyak indeks, oksijen tüketimi, azalmış sistemik vasküler rezistans ve kemoterapi ajanlarının toksik etkileri gibi hem uzun süreli radikal cerrahi hem de hipertermik kemoterapinin etkilerini içeren kompleks fizyolojik bozuklukları kontrol etmelidir.

Anahtar Kelimeler: Sitoredüktif cerrahi; Hipertermik intraperitoneal kemoterapi; Periton yüzey malignitesi; Anestezi yönetimi

\begin{abstract}
The evolvings of alternative treatment choices as cytoreductive surgery combined with hyperthermic chemotherapy for peritoneal surface malignancies creates new responsibilities for anesthesiologists to manage the procedure with sufficient information. To adequately care for these patients, anesthesiologists should control complex malfunctions of physiologic mechanisms, such as hypo-hyperthermia, blood loss, electrolyte abnormalities, coagulopathies, increased cardiac index, oxygen consumption, decreased systemic vascular resistance and toxic effects of chemotherapy agents related with both longer duration of radical surgery and the effects of hyperthermic chemotheraphy.
\end{abstract}

Key words: Cytoreductive surgery; Hyperthermic intraperitoneal chemotherapy; Peritoneal surface malignancy; Anaesthesia management

\section{Giriş}

Periton yüzey maligniteleri; abdominal, pelvik veya ekstraabdominal tümörlere bağl1 peritoneal karsinamatozis (PK), psödomiksoma peritonei ve primer peritoneal tümörlerden oluşan bir grup hastalıktır. Son dönemlere kadar kötü prognozları ve 6 ay kadar düşük yaşam beklentisi nedeniyle palyatif tedavi yaklaşımı öncelikli olmuştur. Uzak organ metastazı olmayan seçilmiş hastalarda bu durum lokalize bir hastalık olarak değerlendirilip sitoredüktif cerrahiperitonektomi (SRC) ve hipertermik intraperitoneal kemoterapi (HIPEK) uygulamaları ile artan sağkalım oranları ve yaşam kalitesi elde edilebilir $(1,2)$.
$\mathrm{Bu}$ uygulamada SRC ile görülebilir tüm tümör dokusu çıkarılır ve intraperitoneal olarak perfüzyonu yapılan kemoterapötik ajanı taşıyan solüsyon $42-43^{\circ} \mathrm{C}$ 'ye 1 sitılarak etkinliği arttılır. Yüksek peritoneal konsantrasyonlarda artmış kemoterapötik etki görülürken ilacın sistemik absorbsiyonu sinırlidır. Bu sayede palyatif yaklaşımın yerini küratif yaklaşım almıştır.

$\mathrm{Bu}$ cerrahi prosedür sirasinda anestezist preoperatif, intraoperatif ve postoperatif dönemde uzun süreli radikal cerrahi ve HİPEK etkilerine bağlı oluşabilecek metabolik ve fizyolojik bozukluklar, kemoterapötiklerin toksik etkileri gibi problemlerle baş edebilecek yeterli bilgi düzeyine sahip olmalıdır (Tablo 1) (2). 
Tablo 1: Sitoredüktif Cerrahi ve Hipertermik İntraperitoneal Kemoterapi (HIPEK) Uygulamalarında Anestezik Yaklaşım

\begin{tabular}{|c|c|c|c|}
\hline $\begin{array}{l}\text { Sitoredüktif Cerrahi } \\
\text { Dönemi }\end{array}$ & $\begin{array}{l}\text { HİPEK Uygulamast } \\
\text { Sirasinda }\end{array}$ & Postoperatif Dönem & $\begin{array}{l}\text { Kemoterapötiklerin } \\
\text { Beklenen yan etkileri }\end{array}$ \\
\hline $\begin{array}{l}\text { Normovolemi sağlamak } \\
6-12 \mathrm{ml} / \mathrm{kg} / \mathrm{s} \mathrm{s} \text { sv1 } \\
\text { replasmanı }\end{array}$ & Normovolemi sağlamak & $\begin{array}{l}\text { İlk } 3 \text { gün yoğun bakımda } \\
\text { takip etmek } \\
\text { İleus } \\
\text { Anastomoz kaçağı } \\
\text { Yara yeri infeksiyonu } \\
\text { Kanama } \\
\text { Tromboz ve pulmoner } \\
\text { emboli ihtimali }\end{array}$ & $\begin{array}{l}\text { Sisplatin, oksaliplatin: } \\
\text { Nefrotoksisite } \\
\text { Hipomagnezemi } \\
\text { Hipokalsemi } \\
\text { Bulant1, kusma } \\
\text { Nörotoksisite } \\
\text { Miyelosupresyon } \\
\text { Anaflaksi (\%10-15) }\end{array}$ \\
\hline $\begin{array}{l}\text { Aşırı 1sı kaybını } \\
\text { önlemek için 1sıtıcılar }\end{array}$ & $\begin{array}{l}\text { Hiperventilasyon, } \\
\text { soğutulmuş intravenöz } \\
\text { kristaloidler }\end{array}$ & $\begin{array}{l}\text { Günde 4-5 L sıv1- } \\
\text { elektrolit kaybını } \\
\text { karş1lamak }\end{array}$ & $\begin{array}{l}\text { Mitomisin C: } \\
\text { Miyelosupresyon } \\
\text { İnterstisyel pnömoni } \\
\text { Bulant, kusma, ishal } \\
\text { Kardiyomiyopati } \\
\text { Hemolitik üremik } \\
\text { sendrom }\end{array}$ \\
\hline $\begin{array}{l}\text { Kanama eğilimi olursa } \\
\text { TDP }\end{array}$ & $\begin{array}{l}\text { Yeterli kardiyak } \\
\text { output/idrar çıkış1 } \\
\text { sağlamak }\end{array}$ & $\begin{array}{l}\text { T4-L2 epidural analjezi } \\
\text { sağlamak }\end{array}$ & $\begin{array}{l}\text { Antrasiklinler } \\
\text { (doksorubisin): } \\
\text { Miyelosupresyon } \\
\text { GIS mukozit } \\
\text { kardiyomiyopati }\end{array}$ \\
\hline $\begin{array}{l}\text { S1k arter kan gazi, } \\
\text { hemotokrit ve elektrolit } \\
\text { takibi ile replasman }\end{array}$ & $\begin{array}{l}\text { S1k arter kan gaz1, } \\
\text { hemotokrit ve elektrolit } \\
\text { takibi ile replasman }\end{array}$ & $\begin{array}{l}\text { Erken enteral nütrisyon } \\
\text { S1k arter kan gazı, } \\
\text { hemotokrit ve elektrolit } \\
\text { takibi ile replasman }\end{array}$ & $\begin{array}{l}\text { 5fluoropirimidinler: } \\
\text { Gastrointestinal Ülserler } \\
\text { Miyelosüpresyon } \\
\text { Nörotoksisite, ataksi } \\
\text { Koroner spazm } \\
\text { Biliyer skleroz } \\
\text { Keratit ve cilt bulguları }\end{array}$ \\
\hline
\end{tabular}

\section{Periton Yüzey Maligniteleri}

Periton yüzey maligniteleri; PK, psödomiksoma peritonei ve primer peritoneal tümörler olarak kategorize edilebilir. PK jinekolojik yada non-jinekolojik tümörlere sekonder periton yüzeyine implante olmuş tümörlerdir. Evre 3-4 over kanserlerinin yaklaşık \%60'1 ve kolorektal kanserlerin yaklaşık \%10'u PK ile birlikte saptanmaktadır. Tedavi edilmemiş PK'da hastaların ortalama yaşamları 7 aydan kısadır (3).

Psödomiksoma peritonei seyrek görülür ve sıklıkla müsinöz appendiks tümörleri ile birlikte müsinöz asit ve peritoneal implant şeklinde görülür. Primer peritoneal kanserler sıklıkla ölümcül seyreden diffüz peritoneal mezotelyoma olarak karşımıza çıkar.

2006'da İtalya'da yapilan 5 . Uluslararası Peritoneal Yüzey Maligniteleri Çalışma Grubu Konferansı'nda varılan konsensus ile hastalara multi-sliced BT, MR ve PET ile yapılan görüntüleme, gerekirse laparoskopi ve bakılan tümör belirteçlerinin sonucu ile SRC ve HIPEK tedavisine karar verilir (4). Kolorektal kaynaklı PK tanısı konan hastalardan 3 ve daha az karaciğer metastazı olan, biliyer obstrüksiyonu olmayan ve sistemik kemoterapiye iyi yanıt vermiş olanlar SRC ve HIIPEK tedavisi için en uygun adaylardır (5). SRC ve HIIPEK tedavisi aktif 
kardiyak şikayeti olmayan yada medikal tedavi ile stabil olan, ekstra-abdominal hastalığ 1 olmayan, yaygın karaciğer metastazı olmayan, retroperitoneal yayılımı olmayan, 70 yaş altı ve peritoneal lezyonu tam ya da tama yakın rezeke edilebilecek hastalara yapılmalıdır (6).

Periton malignitelerinde cerrahi prosedür ve HIPEK tedavisine intraoperatif rezeksiyon öncesi ve rezeksiyon sonrasında yapılan Peritoneal Kanser İndeksi (PKİ); 13 abdominal bölgede yapılan incelemede lezyon çap1 değerlendirilir. Tümör yoksa 0 , tümör çap1 0-5 mm ise 1, tümör çap1 $5 \mathrm{~mm}-5 \mathrm{~cm}$ ise 2 , tümör çap1 $5 \mathrm{~cm}$ 'den büyük ise 3 ile skorlandırılır. Lezyon skorları her 13 bölge için ayrı ayrı değerlendirilir ve 13 bölgedeki skorların toplamı PKI'yi verir. HIIPEK sadece SRC başarılı olarak tamamlanmış hastalara yapilmalidir $(7,8)$.

SRC, intraabdominal makroskopik tümörlerin çıkarılmasını hedefleyen pariyetal ve viseral peritonektomi prosedürüdür. İzole omentektomiden gastrointestinal trakt, pankreas, dalak, safra kesesi, uterus, overler, karaciğerin bir parçasının ve $2.5 \mathrm{~mm}$ 'den büyük lenf nodlarının alınabildiği tüm abdominal rezeksiyonu içerir (9). SRC sonras1 HIPEK tedavisi ile gastrointestinal rekonstrüksiyon yapılmadan önce skar dokusu, adezyon ve anastomoz bölgelerinde malign hücrelerin yayılımını önlemek hedeflenir. HIPEK sırasında kullanılan kemoterapötik ajanlar tümör dokusunda maksimum konsantrasyon ile etki ederken normal dokuya etkisi minimaldir; peritoneal s1v1-plazma bariyerini geçemezler ve peritoneal klirensleri yavaştır. Kemoterapötik ajanlar tümör hücrelerinde DNA tamir mekanizması, protein denatürasyonu ve 1s1-şok protein aktivasyonunu inhibe ederken, hipertermi immün aracilı aktivasyona neden olur $(10,11)$.

HIPEK, suprahepatik ve pelvik kanüller ve bunları bağlayan 1sı değiştirici pompa ile perfüzyonda resirkülasyonu sağlayan kapalı abdominal bir sistemdir. Sitoredüksiyon ve viseral ve pariyetal peritonektomi tamamlandiktan sonra Tenckhoff kateteri, aspiratör ve 1S1 ölçerler yerleştirilerek karın duvarı ve karın kapatılır. Abdomen 3-5 lt siv1 ile doldurulur. Siv1 istenen sicaklığa ulaştığında kemoterapötik ajan sıvıya eklenerek hipertermik kemoperfüzyon başlat1lır. Perfüzyon 1L/ dk olacak şekilde sağlanır. Sitotoksik ajanın perfüzyonu $60-120 \mathrm{dk}$ sürer
(12). HIPEK sirasinda anestezist kemoterapötik ajanların toksisitesi ve taşıyıcı solüsyonların tipi ve miktarı konusunda dikkatli olmalıdır. Taşıyıcı solüsyon olarak genellikle $\% 5$ dekstroz ve izotonik salin tercih edilir. Kullanılan kemoterapötikler içinde sadece oksaliplatinin $\% 5$ dekstroz ile birlikte kullanıldığında sitotoksik metabolit oluşumunun azaldığı gösterilmiştir (13). Yüzde 5 dekstrozun sistemik emilimi ciddi hiperglisemi ve hiponatremiye neden olmaktadır. Ayrıca yapılan çalışmalarda hayvan deneylerinde hipotonik sıvıların kemoterapötiklerin tümör hücre penetrasyonunu arttırdığını göstermesine rağmen insan çalışmalarında gösterilememiştir. Aynı çalışmada hipertonik sıvı kullanılan hastalara oranla hipotonik sivi kullanımında intraperitoneal hemoraji ve trombositopeninin daha sık olduğu gösterilmiştir (14). HIPPEK sırasında kullanılacak kemoterapötik ajana tümörün kaynaklandığ 1 organa göre karar verilir. Gastrointestinal kaynaklı tümörler için mitomisin-C ve 5FU; over kaynaklı tümörler için paklitaksel ve sisplatin kullanılır $(15,16)$.

\section{ANESTEZI YÖNETIMII}

\section{Preoperatif Dönem}

Preoperatif değerlendirmede operasyona alınacak hastaların peritoneal sıvının sistemik absorbsiyonu, kan kaybı, akut böbrek hasarı, elektrolit bozukluğu, asit, hipotermi ve hipertermi ile karşılaşabileceği dikkate alınarak sistemik muayene yapilmalıdır. Kardiyopulmoner değerlendirmede hastaların operasyon sırasında oluşabilecek taşikardi, kardiyak indeks artışı ve oksijen tüketiminde artışı kompanze edebilmeleri prosedüre uygun hasta seçimi açısından dikkate alınmalıdır. Özellikle yaşlı ve risk faktörü olan hastalar ACC-AHA kılavuzuna uygun olarak ileri kardiyak incelemelere alınmalıdır (6). Preoperatif renal değerlendirmede GFR hesaplamas1 hastalarin intraoperatif ve postoperatif böbrek hasarı açısından önemlidir. Preoperatif renal disfonksiyonu olan hastalar perioperatif kardiyovasküler riski de arttırır (17).

\section{Intraoperatif Dönem}

İntraoperatif dönemde cerrahi prosedürün farklı aşamalarda farklı problemler ile 
karşılaşılmaktadır. SRC sırasında ciddi sıv1 kaybı ve ciddi kan kaybına bağlı hipovolemi, uzamış cerrahiye bağlı hipotermi, ciddi kanamaya bağlı koagülopatiler major problemlerdir. HIPEK sirasinda hipertermi ve intraabdominal basınç artışına bağlı kardiyak disfonksiyonlar, artmış metabolik hız ve oksijen tüketimi, akut böbrek hasarı ve kemoterapötik ajanların sitotoksik etkileri major problemlerdir. Cerrahi sirasinda oluşabilecek masif kan kaybını ve postoperatif dönemde abdominal inflamasyona bağlı olarak 3. boşluğa $5000 \mathrm{cc} /$ gün kadar olabilen sıv1 kaybını karşılamak için hastaya en az 2 adet $18 \mathrm{G}-16 \mathrm{G}$ intravenöz kateter veya santral venöz kateter takılmalı ve CVP takibi bu yolla yapılmalıdır. Ayrıca kan basıncı takibi için intraarteriyel kanül takmak gereklidir (18).

Operasyon sirasinda normovolemiyi sağlamak için $6-12 \mathrm{ml} / \mathrm{kg} / \mathrm{s}$ sıvı replasmanı gereklidir. Siv1 replasmanında albumin ve kristaloidler tercih edilmelidir. İdrar çıkışının $50 \mathrm{cc} / \mathrm{s}$ olacak şekilde idamesi için intravenöz (iv) furosemid ve düşük doz dopamin kullanılabilir. Ciddi sıv1 kaybı, yüksek sıv1 devrine bağlı protein kaybı ve hipertermik kemoterapiye bağlı olarak koagülopati görülebilir. Hastalarda INR yüksekliği, AT3 düşüklüğü, uzamış aPTT ve trombositopeni görülmektedir. Koagülopati bekleniyorsa taze donmuş plazma replasmanı normovolemi tedavisinde önemli yer alır. Böbrek hasarını önlemede yeterli intravasküler volüm sağlamak ve böbrek perfüzyonunu korumak hedeflenmelidir (19).

İntraoperatif takip sirasında sivi replasman tedavisi için nabız basıncı değişimi, idrar çıkışı, oluşabilecek laktik asidoz nedeniyle kan gazı analizi (15 dk'da bir) ve saatlik elektrolit takibi gereklidir.

Nguyen ve ark. yayınladığı çalışmada sistemik ve bölgesel perfüzyonu sürdürebilmek ve hemodinamik bozuklukları önleyebilmek için kan volüm kaybının olduğu durumlarda kan replasmanı ve dengeli siv1 tedavisinin önemli rol oynadığı vurgulanmaktadır (20). Yapılan çalışmalarda kan kaybının cerrahiye ve koagülopatiye bağlı olduğu düşünülmüştür. İntraoperatif kan transfüzyonuna ihtiyaç duyulabilecek en önemli risk faktörleri cerrahi sürenin 9 saat üstü olması, preoperatif INR 1.2 'den uzun olmas1, preoperatif hemoglobinin 12.5 altı olması ve PKİ'nin 16 üstü olmasıdır (21).
İntraperitoneal hipertermik siv1 kullanılmas1 ile HIPEK sirasında vücut 1S1s1 ortalama $37.5^{\circ} \mathrm{C}$ dir, $40.5^{\circ} \mathrm{C}$ ye kadar artabilir (22,23). $\quad 40-43^{\circ} \mathrm{C}$ solüsyon kullanılmas koagülopati, aritmi, karaciğer ve renal hasar, periferik nöropati ve nöbete neden olabilecek hipertermiye neden olabilir. Hipertermiden kaçınmak için HIPEK öncesi kontrollü hipotermi sağlanabilir. Ancak hipotermi hastada anestezik ajan farmakokinetiğinde değişim, kan kaybı artışı, cerrahi yara enfeksiyonu ve myokardial etkilere neden olabilir.

Hipertermi sırasında taşikardi, artmış kardiyak indeks, artmış oksijen tüketimi, $\mathrm{ETCO}_{2}$ de artı̧s ve sistemik vasküler rezistansta azalmaya ve ciddi kan basınc1 düşüklügüne neden olur (24). Operasyon sirasinda propranalol, diltiazem hidroklorür ve yüksek doz fentanil kullanımının taşikardiyi baskılayarak kardiyak outputu düşük düzeyde arttırdı ğ1 gösterilmiştir. Hipertermi karşısında vücut 1sıyı vücut yüzeyine transfer edebilmek için yüzeyel kan akımını arttırır ve splenik kan akımını azaltır. Abdominal yüzeyin direkt olarak 1sıya maruz kalmasi ile hipertermiye bağlı splenik damarlarda vazodilatasyon meydana gelir ve abdominal retansiyona neden olur. Bunlara bağl1 olarak kardiyak preload azalır $(23,25,26)$. HIPEK sirasinda ortalama CVP yaklaşık 3-4 mmHg artar (22). Abdominal kan volümünde azalma ve splenik vasküler rezistansta artmaya bağlı olarak kardiyak output artar (27). Operasyon sirasında kardiyovasküler monitorizasyon amaciyla kan basıncı takibi için intraarteriel kanülasyon ve normovolemi takibi için CVP kateteri gereklidir. Kardiyak output/ atım volümü oran1, kardiyak kontraktilite ve s1v1 tedavisi normalizasyonu amaciyla intraoperatif transözofageal EKO kullanılmaktadır (28).

Yapılan bir çalışmada ortalama oksijenizasyon oran1 $\left(\mathrm{PaO}_{2} / \mathrm{FiO}_{2}\right)$ SRC sirasinda 60.7 iken HIPEK sirasinda 50.9'a düştüğü ve HiPEK sonlandırıldıktan sonra en düşük 41.6 olduğu gösterilmiştir (22). HIPEK sırasında SRC dönemi ile karşılaştırıldığında intraabdominal basınç artışına bağlı olarak hava yolu basinc1 artarken paralel olarak $\mathrm{ETCO}_{2}$ 'de artmıştır. İntraabdominal basınç artışı ile fonksiyonel rezidüel kapasite de azalır (20).

HIPEK sirasinda abdomenin siv1 dolması ile intraabdominal basınç artar ve 
inferior vena kava basıs1 ve preload azalmasina neden olur. Abdominal perfüzyon basıncinın optimum düzeyde tutabilmek için intravasküler volümü arttırarak preload ve kardiyak output artışı sağlayarak yada sistemik vasküler rezistans1 vazoaktif medikasyon ile arttırarak ortalama arteryel basıncin $(60 \mathrm{mmHg}$ üstü) artışı sağlanabilir. Maksimal kas gevşemesi ile abdominal rahatlama sağlanması gereklidir $(22,29)$. Adachi ve ark. yaptığ 1 çalışmada hipertermik dönemde vekuronyum potensinde azalma tespit edilmiștir. HİPEK sırasında kas gevşeticilerin efektif kullanımı açısından nöromusküler monitorizasyonun uygulanmas1 önerilmektedir (30).

HIPEK sırasında karşıllaşılabilecek metabolik bozukluklar taşıyıcı solüsyonlara ve hipertermiye bağlıdır. Hipertermi metabolik aktiviteyi, kalp hızını, $\mathrm{CO}_{2}$ üretimini ve $\mathrm{O}_{2}$ tüketimini arttırır (22). Taşıma solüsyonu olarak ringer laktat ve $\% 5$ dekstroz kullanılan hastalar karşılaștırıldığında \%5 dekstroz kullanılan hastalarda hiperglisemi, hiponatremi ve metabolik asidoz ile karşılaşılmış, laktat düzeyi de bu hastalarda artıș göstermiștir (31). Bazı çalışmalarda görülen dilüsyonel hiponatreminin serebral ödeme neden olarak mortalite ve morbiditeyi arttırdığ gösterilmiştir (32). Hipervolemik hiponatremi iv furosemid ve iv salin replasmanı ile tedavi edilebilir. HIPEK sırasında görülebilen hiperlaktatemi, hipergliseminin neden olduğu glikolizis sırasında oluşan tip A laktat'tan daha çok doku hipoperfüzyonuna neden olan tip B laktat artışı olarak karşımıza çıkar $(31,32)$. Sisplatin arac1lı böbrek hasarı ile hipomagnezimi ile görülebilen intraoperatif aritmilere neden olduğu gösterilmiştir (29).

HIPEK sirasinda nefrotoksik kemoterapötiklerin kullanımı, abdominal hipertansiyon ve abdominal sıvı geçişine bağlı intravasküler volüm açığı nedeniyle \%1.3\%5.7 hastada akut böbrek hasarı görülmektedir. Böbrek hasarı genellikle multifaktöriyel, geri dönüşümlü ve cisplatin (240 mg) kullanılan hastalarda görülmektedir $(19,34)$.

\section{Postoperatif Dönem}

HİPEK sonrası hastalar yoğun bakım ünitesinde takip edilmelidir. Peroperatif süreçte multiorgan disfonksiyonu adayı olan hastaların sürekli pulse oksimetri ve kardiyak monitorizasyonu yapılmalıdır. GIS perforasyonu, anastomoz kaçağı, safra kaçağı, fistül oluşumu, pankreatit, postoperatif kanama, derin ven trombozu ve pulmoner emboli açısından yakın takip edilmelidir. Kullanılan kemoterapötiklerden mitomisin-C, lökopeni ve transaminaz yüksekliği yanında özellikle preoperatif radyoterapi almış hastalarda anastomoz kaçağı riskini arttırır (35).

HIPEK sonras1 vazodilatasyon beklenen bir durumdur. Operasyon sonrası ilk 72 saat boyunca hastaların abdominal drenlere ve 3. boşluğa sıvı kaybı yaklaşık 5.7 lt/gündür. Hipotansiyon tedavisi için hastaların iv sıv1 replasmanı dikkatli yapılmalı ve gerekirse vazokonstrüktif tedavi (norepinefrin, vazopressin) uygulanmalıdır. Operasyon sırasında başlayan protein kaybına bağlı albumin düşüklüğü postoperatif dönemde de devam eder. Elektrolit normalizasyonu ve hematolojik replasman postoperatif takipte önemlidir.

HİPEK sonrası ileus oluşması ciddi bir problemdir. Hastaların beslenme rejimleri açısından yeterli çalışma yoktur; ancak Arakealin ve ark. yaptığ 1 retrospektif çalışmada hastaların postoperatif 7-11. gün arasında oral beslenmeyi tolere edebildiği gösterilmiştir. Epidural analjezi kullanımının postoperatif ileus riskini azalttı̆g 1 gösterilmiştir (36).

SRC ve HİPEK cerrahisinde ağr1 tedavisi hasta konforu ve postoperatif pulmoner fonksiyonun devamı için gereklidir. Postoperatif analjezi için torakal epidural kateter s1k kullanılan bir yöntemdir. Opioid kullanımını ve opioidlere bağlı gelişebilen barsak atonisi riskini azaltır, barsak motilitesini arttırır ve erken fiziksel aktivite ve solunum egzersizlerine olanak sağlar $(22,37)$.

\section{SRC ve HIPEK Sonrası Sonuçlar, Mortalite ve Morbidite}

Verwall ve ark. yaptıkları çalışmada kolorektal kansere sekonder PK'de sistemik kemoterapi ile karşılaştırıldığında SRC ve HIPEK tedavisi alan hastaların ortalama genel sağkalımların (GS) 22 aya kadar uzadığını göstermişlerdir (38). Spiliotis ve ark. yayınladığı prospektif çalışmada over kanserine sekonder PK olgularında sistemik kemoterapi sonrası SRC ve HIPEK uygulanan hastalar ile SRC sonras1 sistemik kemoterapi uygulanan hastalar karşı- 
laştırıldığında HIPEK uygulanan hastalarda anlamlı olarak ortalama GS 19.5 aya kadar uzamış ve 3 yıllık GS \%50 olarak bulunmuştur. SRC ve sistemik kemoterapi uygulanan hastalarda ortalama GS 11.2 ay, 3 y1llık GS \%18 olarak bulunmuştur (39). Yan ve ark.'nın yayınladığı derlemede SRC ve HIPEK uygulanan primer PK ve diffüz malign peritoneal mezotelyomalı hastalarda GS'nin 59 aya kadar uzadığ 1 ve 5 yıllık GS'nin \%47 olduğu gösterilmiştir (40).

SRC ve HIPEK tedavisi uygulanan hastalarda morbiditeyi etkileyen major risk faktörleri; 21 üstü PKİ, 3 üzeri ASA, 10 saatten uzun operasyon süresi, sol üst peritonektomi, kolostomi, ileostomi ve 6 Ü'den fazla eritrosit süspansiyonu replasmanıdır (41). Sugarbaker ve ark. yaptıkları prospektif analizde psödomiksoma peritonei tanıs1 konan 350 hastada mitomisin-C kullanılarak yapılan SRC ve HIPEK tedavisi ile 30 günlük hastane mortalitesinde $\% 19$ 'dan $\% 2$ 'ye kadar ve morbiditede \%35'den \%5'e kadar azalma olduğu gösterilmiştir (42).

\section{Operasyon Odası Personeli İçin Güvenlik Önlemleri}

HİPEK 3 temel teknikle sağlanır: açık karın tekniği, kapalı karın tekniği ve peritoneal boşluk genişletici teknik. Kullanılan bu teknikler içinde kemoterapötik ajanlara maruziyeti en aza indiren kapalı karın tekniğidir. Stuart ve ark.'nın yaptıkları çalışmada 10 farklı cerrahi sırasında açık karın tekniği ve mitomisin-C ile yapilan kemoperfüzyon sirasinda cerrah ve perfüzyonist idrar örneklerinde ve bakılan hava örneğinde yüksek miktarda kemoterapötik saptanmıştır (43).

\section{Sonuc}

Günümüzde hasta seçimi, SRC ve HIIPEK için gerekli optimal zamanlama, perfüzat sıcaklığ 1 ve seçilecek kemoterapötik ajan ile ilgili bir fikir birliği sağlanamamıştır. Birçok merkez 'National Cancer Institute' tarafindan belirlenen toksisite kriterleri/ evreleme sistemini kullanmaktadır. Ancak tek evreleme sistemi ile mortalite ve morbidite hakkında bilgi sahibi olmak zordur.

SRC ve HIPEK periton yüzey malignitesi olan seçilmiş hastalarda standart tedavi olarak önerilmektedir. Uzamış radikal cerrahi, ciddi s1v1, kan, protein ve 1s1 kaybına neden olurken HIPPEK artmış intraabdominal basınç ve metabolik hız ile hipertermiye neden olmaktadır. Bu nedenle temel hedef hastanın santral venöz basıncını, invaziv arter basıncını, vücut 1sısını, idrar çıkışını, elektrolitlerini, kan gazı takiplerini ve kanamaya eğilim oluşursa koagülasyon parametrelerini monitorize ederek yeterli doku perfüzyonu ve oksijenizasyonu sağlayacak şekilde volüm replasmanı sağlamaktır. Postoperatif opioid tüketimini ve mekanik ventilasyonu azaltmak için yeterli ağrı kontrolü açısından torakal epidural analjezi önerilmektedir. Tüm süreç boyunca cerrah ile anestezist arasındaki iletişimin hasta yararı açısından önemi vurgulanmalıdır.

\section{Çıkar Çatışması: Yok}

\section{Kaynaklar}

1. Macrì A. New approach to peritoneal surface malignancies. World J Gastrointest Oncol 2010;2:911

2. Web CA, Weyker PD, Moitra VK, Raker RK. An Overview of Cytoreductive Surgery and Hyperthermic Intraperitoneal Chemoperfusion for the Anesthesiologist Anesth Analg 2013;116:924-31

3. Chua TC, Liauw W, Saxena A, et al. Evolution of locoregional treatment for peritoneal carcinomatosis: single-center experience of 308 procedures of cytoreductive surgery and perioperative intraperitoneal chemotherapy. Am J Surg 2011;201:149-56

4. Yan TD, Morris DL, Shigeki K, Dario B, Marcello D. Preoperative investigations in the management of peritoneal surface malignancy with cytoreductive surgery and perioperative intraperitoneal chemotherapy: Expert consensus statement. J Surg Oncol 2008;98:224-7

5. Esquivel J, Sticca R, Sugarbaker P, et al; Society of Surgical Oncology Annual Meeting. Cytoreductive surgery and hyperthermic intraperitoneal chemotherapy in the management of peritoneal surface malignancies of colonic origin: a consensus statement. Society of Surgical Oncology. Ann Surg Oncol 2007; 14:128-33

6. Fleisher LA, Beckman JA, Brown KA, et al. ACC/AHA 2007 guidelines on perioperative cardiovascular evaluation and care for noncardiac surgery: executive summary-a report of the American College of Cardiology/American Heart Association Task Force on Practice Guidelines. Anesth Analg 2008;106:685-712

7. Harmon RL, Sugarbaker PH. Prognostic indicators in peritoneal carcinomatosis from gastrointestinal cancer. Int Semin Surg Oncol 2005;2:3-10

8. Sugarbaker PH, Chang D. Results of treatment of 385 patients with peritoneal surface spread of appendiceal malignancy. Ann Surg Oncol 1999;6:727-31 
9. Van de Vaart PJ, Van der Vange N, Zoetmulder FA, et al. Intraperitoneal cisplatin with regional hyperthermia in advanced ovarian cancer: pharmacokinetics and cisplatin-DNA adduct formation in patients and ovarian cancer cell lines. Eur J Cancer 1998;34:148-54

10. Christophi C, Winkworth A, Muralihdaran V, Evans $\mathrm{P}$. The treatment of malignancy by hyperthermia. Surg Oncol 1998;7:83-90

11. González-Moreno S, González-Bayón LA, OrtegaPérez G. Hyperthermic intraperitoneal chemotherapy: rationale and technique. World $\mathrm{J}$ Gastrointest Oncol 2010;2:68-75

12. Witkamp AJ, de Bree E, Van Goethem R, Zoetmulder FA. Rationale and techniques of intra operative hyperthermic intraperitoneal chemotherapy. Cancer Treat Rev 2001;27:365-74

13. Jerremalm E, Hedeland M, Wallin I, Bondesson U, Ehrsson H. Oxaliplatin degradation in the presence of chloride: identification and cytotoxicity of the monochloro monooxalato complex. Pharm Res 2004;21:891-4

14. Elias D, El Otmany A, Bonnay M, et al. Human pharmacokinetic study of heated intraperitoneal oxaliplatin in increasingly hypotonic solutions after complete resection of peritoneal carcinomatosis. Oncology 2002;63:346-52

15. Teo M, Foo KF, Koo WH, Wong LT, Soo KC. Lessons learned from initial experience with peritonectomy and intra-peritoneal chemotherapy infusion. World J Surg 2006;30:2132-5

16. Witkamp AJ, de Bree E, Kaag MM, Boot H, Beijnen JH, Van Slooten GW. Extensive cytoreductive surgery followed by intra-operative hyperthermic intraperitoneal chemotherapy with mitomycin-C in patients with peritoneal carcinomatosis of colorectal origin. Eur J Cancer 2001;37:979-84

17. Brosius FC III, Hostetter TH, Kelepouris E, et al. American Heart Association Kidney and Cardiovascular Disease Council; Council on High Blood Pressure Research; Council on Cardiovascular Disease in the Young; Council on Epidemiology and Prevention; Quality of Care and Outcomes Research Interdisciplinary Working Group. Detection of chronic kidney disease in patients with or at increased risk of cardiovascular disease: a science advisory from the American Heart Association Kidney and Cardiovascular Disease Council; the Councils on High Blood Pressure Research, Cardiovascular Disease in the Young, and Epidemiology and Prevention; and the Quality of Care and Outcomes Research Interdisciplinary Working Groupdeveloped in collaboration with the National Kidney Foundation. Circulation 2006;114:1083-7

18. Esquivel J, Angulo F, Bland RK, Stephens AD, Sugarbaker PH. Hemodynamic and cardiac function parameters during heated intraoperative intraperitoneal chemotherapy using the open "coliseum technique." Ann Surg Oncol 2000;7:296300

19. Webb TS, Allen DS. Perioperative renal protection. Contin Educ Anaesth Crit Care Pain 2008;8:176-80

20. Ninh T. Nguyen, Bruce M. Wolfe. The Physiologic Effects of Pneumoperitoneum in the Morbidly Obese. Ann Surg 2005; 241:219-26
21. Saxena A, Yan TD, Chua TC, et al. Factors for massive blood transfusion in cytoreductive surgery: a multivariate analysis of 243 procedures. Ann Surg Oncol 2009;16:2195-203

22. C. Schmidt, M. Creutzenberg, P. Piso, J. Hobbhahn and M. Bucher. Peri-operative anaesthetic management of cytoreductive surgery with hyperthermic intraperitoneal chemotherapy. Anaesthesia 2008;63:389-95

23. Kanakoudis F, Petrou A, Michaloudis D, et al. Anaesthesia for intra-peritoneal perfusion of hyperthermic chemotherapy. Haemodynamic changes, oxygen consumption and delivery. Anaesthesia 1996;51:1033-6

24. Kim YD, Lake CR, Lees DE, et al. Hemodynamic and plasma catecholamine responses to hyperthermic cancer therapy in humans. Am J Physiol 1979;237:H570-4

25. Shime N, Lee M, Hatanaka T. Cardiovascular Changes During Continuous Hyperthermic Peritoneal Perfusion. Anesth Analg 1994;78:938-42

26. Kamal JM, Elshaikh SM, Nabil D, Mohamad AM. The perioperative course and anesthetic challenge for cytoreductive surgery with hyperthermic intraperitoneal chemotherapy. Egypt J Anaesth 2013;29:311-8

27. Bickel A, Arzomanov T, Ivry S. Reversal of adverse hemodynamic effects of pneumoperitoneum by pressure equilibration. Arch Surg 2004;139:1320-5

28. Cafiero T, Di Iorio C, Di Minno RM, Sivolella G, Confuorto G. Non-invasive cardiac monitoring by aortic blood flow determination in patients undergoing hyperthermic intraperitoneal intraoperative chemotherapy. Minerva Anestesiol 2006;72:207-15

29. Cheatham ML, White MW, Sagraves SG, Johnson JL, Block EF. Abdominal perfusion pressure: a superior parameter in the assessment of intraabdominal hypertension. J Trauma 2000;49:621-6

30. Adachi T, Shinomura T, Nomura R. Duration of vecuronium induced neuromuscular blockade is shortened during hyperthermic intraoperative intraperitoneal chemotherapy. Br. J. Anaesth 2003;91:160-1

31. De Somer F, Ceelen W, Delanghe J, et al. Severe hyponatremia, hyperglycemia, and hyperlactatemia are associated with intraoperative hyperthermic intraperitoneal chemoperfusion with oxaliplatin. Perit Dial Int 2008;28:61-6

32. Rueth NM, Murray SE, Huddleston SJ, Abbott AM, Greeno EW, Kirstein MN. Severe electrolyte disturbances after hyperthermic intraperitoneal chemotherapy: oxaliplatin versus mitomycin C. Ann Surg Oncol 2011;18:174-80

33. Thix CA, Königsrainer I, Kind R, Wied P, Schroeder $\mathrm{TH}$. Ventricular tachycardia during hyperthermic intraperitoneal chemotherapy. Anaesthesia 2009;64:1134-6

34. Kusamura S, Baratti D, Younan R, et al. Impact of cytoreductive surgery and hyperthermic intraperitoneal chemotherapy on systemic toxicity. Ann Surg Oncol 2007;14:2550-8

35. Loggie BW, Fleming RA. Complications of heated intraperitoneal chemotherapy and strategies for prevention. Cancer Treat Res 1996;82:221-33 
36. Arakelian E, Gunningberg L, Larsson J, Norlén K, Mahteme H. Factors influencing early postoperative recovery after cytoreductive surgery and hyperthermic intraperitoneal chemotherapy. Eur J Surg Oncol 2011;37:897-903

37. Miao N, Pingpank JF, Alexander HR, et al. Cytoreductive surgery and continuous hyperthermic peritoneal perfusion in patients with mesothelioma and peritoneal carcinomatosis: hemodynamic, metabolic, and Anesthetic Considerations. Ann Surg Oncol 2009;16:334-44

38. Verwaal VJ, van Ruth $S$, de Bree E, et al. Randomized trial of cytoreduction and hyperthermic intraperitoneal chemotherapy versus systemic chemotherapy and palliative surgery in patients with peritoneal carcinomatosis of colorectal cancer. J Clin Oncol 2003;21:3737-43

39. Spiliotis J, Vaxevanidou A, Sergouniotis F, Lambropoulou E, Datsis A, Christopoulou A. The role of cytoreductive surgery and hyperthermic intraperitoneal chemotherapy in the management of recurrent advanced ovarian cancer: a prospective study. J BUON 2011;16:74-9
40. Yan TD, Deraco M, Baratti D, et al. Cytoreductive surgery and hyperthermic intraperitoneal chemotherapy for malignant peritoneal mesothelioma: multi-institutional experience. J Clin Oncol 2009;27:6237-42

41. Saxena A, Yan TD, Chua TC, Morris DL. Critical assessment of risk factors for complications after cytoreductive surgery and perioperative intraperitoneal chemotherapy for pseudomyxoma peritonei. Ann Surg Oncol 2010;17:1291-301

42. Sugarbaker PH, Alderman R, Edwards G, Marquardt CE, Gushchin V, Esquivel J. Prospective morbidity and mortality assessment of cytoreductive surgery plus perioperative intraperitoneal chemotherapy to treat peritoneal dissemination of appendiceal mucinous malignancy. Ann Surg Oncol 2006;13:63544

43. Stuart OA, Stephens AD, Welch L, Sugarbaker PH. Safety monitoring of the coliseum technique for heated intraoperative intraperitoneal chemotherapy with mitomycin C. Ann Surg Oncol 2002;9:186-91 